\title{
Experimental studies of autoignition and soot formation of diesel surrogate fuels
}

Proc IMechE Part D:

J Automobile Engineering

227(5) 656-664

(c) IMechE 2013

Reprints and permissions:

sagepub.co.uk/journalsPermissions.nav DOI: $10.1177 / 0954407012458402$

pid.sagepub.com

(SAGE

\author{
Alvaro Diez ${ }^{1,2}$, Roy J Crookes' and Terese Løvås ${ }^{1,3}$
}

\begin{abstract}
Computational simulation has undergone vast development for internal-combustion engine research as a time- and costsaving tool. Yet combustion simulation for conventional hydrocarbon petroleum fuels faces difficult challenges since such fuels have very complex compositions, consisting of many different molecular species, for which data are sparse. The use of surrogate fuels for combustion simulation could provide a solution to this problem. In this investigation, $n$-heptane and mixtures of $n$-heptane and toluene were studied within a broad range of potential surrogate diesel fuels, and the ignition delay and soot formation trends were compared with those of diesel fuel. Ignition delays show good agreement with those for diesel fuel and it was also possible to replicate partially the soot formation behaviour for certain engine conditions. Further investigation is needed to find a surrogate fuel that closely matches over the range of operating conditions of a diesel engine.
\end{abstract}

\section{Keywords}

Autoignition, soot formation, heptane, toluene, surrogate, diesel

Date received: II April 2012; accepted: 24 July 2012

\section{Introduction}

Research on automotive engines has been driven by a worldwide necessity to manage the consumption of fossil fuel supplies. Moreover, to protect the environment, more stringent regulation of vehicle emissions has been imposed in the European Union and countries such as the USA and Japan. Nowadays, research on diesel engines is focused on new types of combustion mode capable of reducing simultaneously nitrogen oxides $\left(\mathrm{NO}_{x}\right)$ and soot emissions as well as the introduction of new alternative fuels. A way to reduce the time and cost of engine research is the use of computational simulation tools. These tools should be reliable and realistic. In the case of combustion simulation for conventional hydrocarbon petroleum fuels, these requirements may well be difficult to meet, since such fuels have a very complex composition, consisting of many molecular species. These might not have been extensively investigated and crucial data might be unavailable. The use of surrogate fuels for combustion simulation could be a solution to this problem. These would have known physical and chemical properties and combustion characteristics similar to those of the real fuel, enabling them to be used in combustion simulations.
In this paper, autoignition and soot formation results are presented for $n$-heptane and mixtures of $n$-heptane and toluene. Since $n$-heptane has a cetane number similar to that of diesel fuel and since toluene would act as an aromatic soot promoter, these were chosen as a first step to the development of a suitable surrogate diesel fuel, which most probably will contain three or four components adding long-chain hydrocarbons such as dodecane or hexadecane (to be assessed later) to those used here.

For autoignition investigations of surrogate fuels with cetane numbers comparable with that of diesel fuel, the ignition behaviour of the fuels will probably not match over the wide operating range of a conventional high-speed direct-injection diesel engine. For example, in other studies with the $n$-alkane examined

\footnotetext{
'Queen Mary University of London, London, UK

${ }^{2}$ IYTE Izmir Institute of Technology, Turkey

${ }^{3}$ Norwegian University of Science and Technology, Trondheim, Norway

Corresponding author:

Alvaro Diez, IYTE Izmir Institute of Technology, Urla - Izmir 35430,

Turkey.

Email: alvarodiez@iyte.edu.tr
} 
here, the significantly higher volatility of $n$-heptane could lead to differences in liquid spray penetration and vaporization and, consequently, in local fuel-to-air ratios. $^{1}$ However, even under conditions where the fuel-air distributions match, the ignition behaviours of $n$-heptane and diesel fuel may also differ. This is because the first stage (low-temperature) heat releases of $n$-heptane and diesel fuel will most probably exhibit different dependences on the temperature and pressure. Similar limitations would be expected with any singlecomponent surrogate. ${ }^{1}$

Measurements of the ignition delay of different surrogate fuels and mixtures have been carried out widely in recent years. One of the most commonly used experimental set-ups for this purpose is a high-pressure shock-tube facility. Using this facility, ${ }^{2,3} n$-heptane ignition delay measurements have been obtained by means of pressure data as well as by $\mathrm{OH}$ and $\mathrm{CH}$ chemiluminescence. Also, $n$-heptane, as a typical long-chain hydrocarbon, and some mixtures of $n$-heptane and toluene, as representatives of the diesel fuel aromatic fraction, have been used for experimental and numeri$\mathrm{cal}^{4,5}$ analysis of the homogeneous charge compression ignition (HCCI) autoignition process. Davidson et al. ${ }^{6}$ investigated toluene-air mixture combustion under engine-relevant conditions. Mittal and Sung $^{7}$ studied autoignition of toluene at very high temperatures in a rapid compression machine. More recently, autoignition experiments with toluene-doped $n$-heptane have been carried out in a high-pressure shock tube, ${ }^{8}$ where, as with previous observations, longer ignition delays were observed for lean-fuel mixtures. Moreover, the kinetics involving toluene did not affect the ignition delay of the main fuel ( $n$-heptane and iso-octane) when toluene was used in relatively small quantities (not more than 10 vol \%).

Soot formation in diesel engines has been extensively studied. The processes which follow fuel injection where a partially premixed turbulent mixing-limited flame exists present a complex state, and this can be used to model how the physical parameters can affect soot formation. If most of the soot particles are formed in fuelrich regions, an increase in oxygen either in the fuel or through premixing would be expected to reduce soot formation. This is not always so since oxygen is almost unavoidably connected with the temperature, which has an exponential influence in both soot formation and oxidation kinetics. ${ }^{9}$ Soot formation of toluene and $n$-heptane fuels has been investigated in shock-tube ${ }^{10,11}$ experiments which showed that the soot formed in toluene pyrolysis for mixtures where toluene was varied between $30 \%$ and $100 \%$. Recent investigations of soot formation in diffusion flames ${ }^{12}$ suggested that a small amount of toluene had a minimal effect on soot levels in these conditions even though toluene had been thought to have a dominant role in soot formation.

As part of a search for a suitable surrogate diesel fuel, an experimental investigation of the ignition characteristics and soot emission trends of different single-component and multiple-component mixtures has been undertaken, with candidate fuels including high- and lower-cetane-number alkanes. The fuel mixtures described here have a normal-alkane hydrocarbon with a cetane number closer to that of diesel fuel, with the addition of toluene as an aromatic component in low percentages following the European Standard for diesel. $^{13}$

\section{Experimental set-up}

Ignition experiments were carried out in an optical combustion chamber. This facility is essentially an auxiliary chamber fitted with inspection fused quartz windows. The optical chamber is connected via a passage to one cylinder of a four-cylinder diesel engine in which a flat-top piston replaces the standard piston. The chamber contribution to the clearance volume corresponds to the removed piston bowl. The engine is run on standard diesel fuel, using the other three cylinders fed from a standard fuel pump to establish the speed while motoring the optical chamber. The chamber is fitted with a piezoelectric pressure transducer for cylinder pressure and energy conversion rate analysis. The chamber has an internal hollow ring that is used for two purposes. One is the modification of the compression ratio by changing the free volume in the chamber by varying the internal diameter of the ring; the second is the introduction of a swirl movement in the chamber. For the latter purpose, three slots are cut in the ring with different radial angles to modify the swirl.

Figure 1(a) and (b) shows the line drawing of the experimental set-up and a schematic diagram of the optical-access chamber respectively, and Table 1 shows the engine specifications and compression ratio after the modification. The optical chamber provides a compression ignition zone which is optically accessible, readily set up and controlled and operated under conditions close to those of a running engine. Like all other diagnostic strategies, such as shock tubes and optical engines, it inevitably creates conditions which differ somewhat from the target but in this case provides a convenient means of comparing fuels. The chamber is fitted with a high-pressure common-rail injection system capable of an injection pressure of up to $160 \mathrm{MPa}$. The injector is fitted in the centre of one of the circular ends of the chamber. The rail is fitted with a pressure sensor, the signal of which is sent to a custom-built electronic control unit (ECU) to control the injection pressure. The common rail has four outlets, three of which are blanked off while the remaining outlet connects it with the injector. Table 2 shows the specification of the injector used in this study. A LabVIEW custom-built program controls the pump and the injector driver. The ECU is fed with the shaft encoder and top dead centre signals and controls the injection timing and duration. 


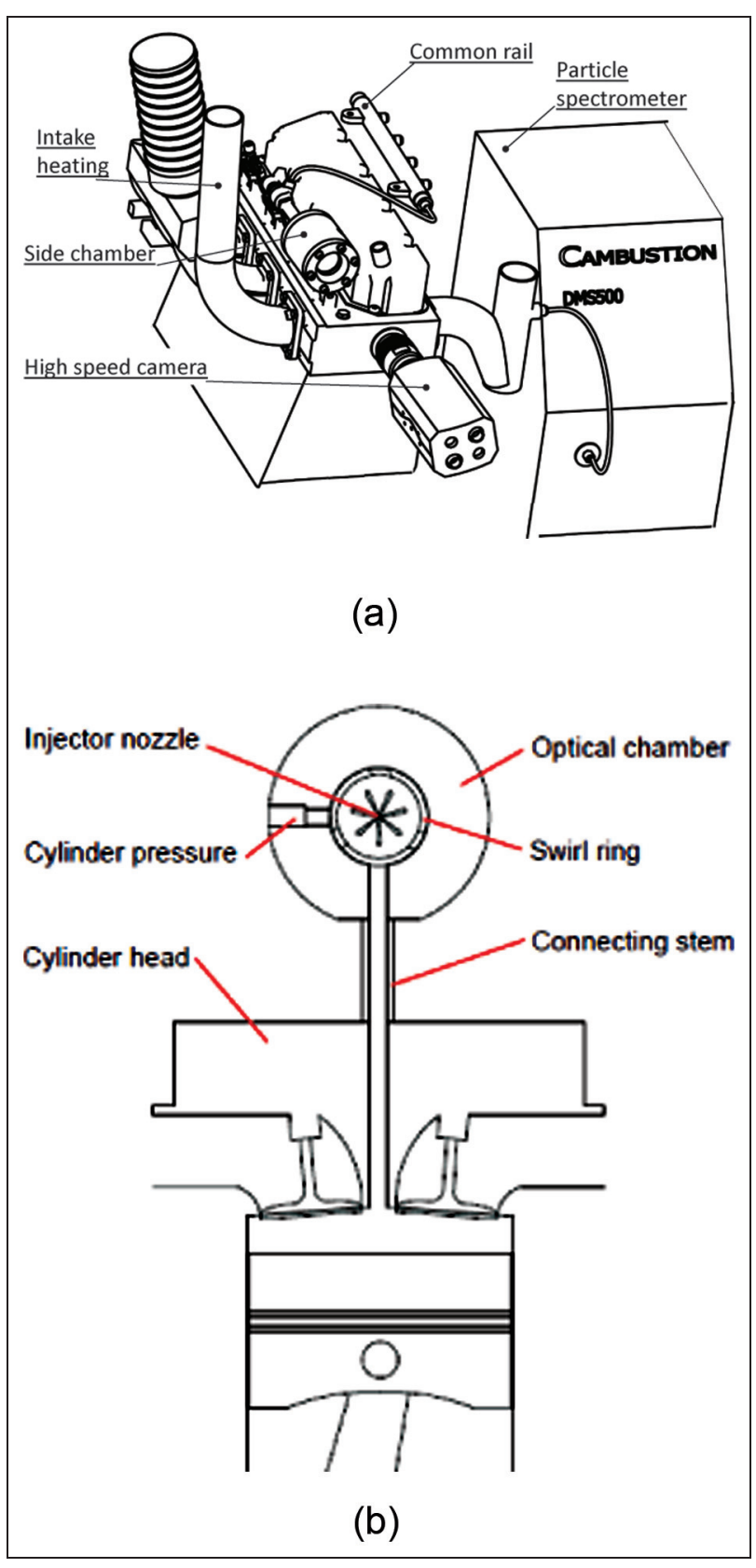

Figure I. (a) Line drawing and (b) schematic diagram of the optical combustion chamber.

\section{Cylinder pressure and exhaust measurements}

The injection timings were varied and the cylinder pressure data were recorded; the ignition delays were calculated by determining the start of injection (SOI) and the start of combustion (SOC). From the cylinder pressure data, the SOI was determined by the signal sent from the ECU to the injector driver, accounting for a delay of $300 \mu$ s for all the fuels in this study which was measured optically at a rate of 20,000 frames/s. From the cylinder pressure data, the bulk gas temperature was calculated as well as the energy conversion rate. When analysing the pressure traces of the firing cycles, after reaching the peak pressure, a pressure drop was experienced, which was more prominent for earlier
Table I. Engine specifications.

\begin{tabular}{ll}
\hline Engine & $\begin{array}{l}\text { Ford in-line overhead-valve } \\
\text { (modified) engine }\end{array}$ \\
Bore & $93.67 \mathrm{~mm}$ \\
Stroke & $90.54 \mathrm{~mm}$ \\
Connecting-rod length & $0.1536 \mathrm{~m}$ \\
Engine capacity & $624 \times 10^{-6} \mathrm{~m}^{3}$ \\
Compression ratio & $16.1: 1$ \\
Engine speed for testing & $1000 \mathrm{r} / \mathrm{min}$ \\
\hline
\end{tabular}

Table 2. Injector characteristics.

\begin{tabular}{ll}
\hline Injector & Siemens Lynx injector \\
Injection pressure & $80 \mathrm{MPa}$ \\
Number of holes & 7 \\
Cone angle & $152^{\circ}$ \\
Hole diameter & $110 \mu \mathrm{m}$ \\
Type & Microsac \\
\hline
\end{tabular}

injection timings. This effect linked with the piston motion in the main cylinder. Tests in which both pressures were monitored showed a short lag and a fractionally lower magnitude in the chamber, possibly caused by transfer through the short connecting tube. The energy conversion rate calculations were distorted, and the usual information on premixed and diffusion combustion phases was not recovered. For the SOC determination, an inflection in the cylinder pressure trace showing a sudden increase in the pressure-rise rate was taken. The point where both the first and the second pressure derivative curves suddenly displayed rises was also at the same point. The SOC values were thus obtained from a first pressure derivative analysis.

For the measurement of soot particle number-size distributions a differential mobility particle spectrometer (DMS500) was connected to the exhaust manifold approximately $50 \mathrm{~cm}$ downstream of the exhaust valve of the target cylinder. The sample gas from the isolated cylinder was drawn into a diluter via a heated sample line to prevent condensation and to freeze the particle dynamics. ${ }^{14}$ For all experiments, the line was heated to $80^{\circ} \mathrm{C}$. The first dilution ratio was $4: 1$ to lower the dew point of the air so that condensation did not occur, and the second dilution ratio was 200:1 to obtain the best signal-to-noise ratio for the instrument under these conditions. It has been observed ${ }^{14}$ that increasing the dilution ratio reduces the nucleation of new particles and the particle growth. The spectrometer measures particles in the size range $5-1000 \mathrm{~nm}$ at $200 \mathrm{~ms}$ response with output data range up to $10 \mathrm{~Hz}$. The particle number-size and the particle mass concentration distributions shown in the following sections were averaged from 10 firing cycles, representative of each test condition. The particle number concentration is presented in terms of $\mathrm{d} N / \mathrm{d}\left\{\log \left[D_{\mathrm{p}}(\mathrm{nm})\right]\right\}$, with units of $N$ 
Table 3. Chemical properties and physical characteristics of the fuels at standard atmospheric conditions.

\begin{tabular}{|c|c|c|c|}
\hline \multirow[t]{2}{*}{ Property (units) } & \multicolumn{3}{|c|}{ Value for the following fuels } \\
\hline & Diesel & Heptane & Toluene \\
\hline Chemical formula & $\mathrm{C}_{n} \mathrm{H}_{1.8 n}$ & $\mathrm{C}_{7} \mathrm{H}_{16}$ & $\mathrm{C}_{7} \mathrm{H}_{8}$ \\
\hline Density $\left(\mathrm{kg} / \mathrm{m}^{3}\right)$ & $827-840$ & 680 & 867 \\
\hline Lower heating value $(\mathrm{MJ} / \mathrm{kg})$ & 42.5 & 44.8 & 40.6 \\
\hline Cetane number & 52 & 55 & - \\
\hline Initial boiling point $\left({ }^{\circ} \mathrm{C}\right)$ & 169 & 98 & III \\
\hline
\end{tabular}

$\left(\mathrm{cm}^{-3}\right)$. The reason for this is to allow easy integration over any size range to give a total particle concentration; $\mathrm{d} N / \mathrm{d}\left\{\log \left[D_{\mathrm{p}}(\mathrm{nm})\right]\right\}$ is chosen as the quantity such that the area under the graph gives $N$ according to

$$
N=\int_{D_{\mathrm{p} 1}}^{D_{\mathrm{p} 2}} \frac{d N}{d\left\{\log \left[D_{\mathrm{p}}(\mathrm{nm})\right]\right\}} d\left\{\log \left[D_{\mathrm{p}}(\mathrm{nm})\right]\right\}
$$

where

$D_{\mathrm{p}}=$ particle diameter $(\mathrm{nm})$

$N=$ number of particles

For the total particle mass, the integration of the mass concentration over the size range is applied.

\section{Optical techniques}

A high-speed video camera was used to record the fuel spray during the injection period and the combustion images. In order to visualize the injected spray, a highoutput fibre-optic illuminator system was employed. A Phantom V 4.3 digital camera equipped with a highspeed colour complementary metal-oxide-semiconductor sensor was used, which records up to 90,000 frames/s. The recording speed for this study was 6000 frames/s which corresponds to 1 crank angle (CA) per frame and a derived error of $167 \mu \mathrm{s}$. The image resolution was $256 \times 256$ pixels. A Nikon $60 \mathrm{~mm} f=2.8$ lens was mounted on the camera. The SOC was determined by the first traces of luminosity in the combustion chamber, a blue-like low intensity glow, preceding the highluminosity flames from the soot particles. The ignition delays so defined were derived and compared with those calculated from the cylinder pressure data.

\section{Fuels investigated}

In addition to diesel fuel, $n$-heptane and mixtures of $n$-heptane and ( 5 mass $\%$ and 10 mass $\%$ ) toluene were tested. The single straight-chain molecule component was chosen since $n$-heptane has a cetane number similar to that of diesel fuel and since toluene would act as an aromatic soot promoter. Because the injection duration was kept constant and because the mixture densities were different, the quantities of liquid injected varied within calculated limits. Table 3 shows the fuel properties of the reference fuels and Table 4 shows the properties of the mixtures investigated.

\section{Results}

\section{Autoignition results}

The ignition delay was determined from the cylinder pressure as well as from the high-speed imaging videos. The pressure traces for diesel fuel and the heptanetoluene mixtures for an injection pressure of $80 \mathrm{MPa}$ at an SOI of $15^{\circ} \mathrm{CA}$ before top dead centre (BTDC) are illustrated in Figure 2. All the surrogate fuels show very similar profiles. Although the ignition delay for the fuels investigated was shorter than for diesel fuel, the cylinder peak pressure was higher, indicating that more fuel burned during the premixed combustion phase. This could be explained as vaporization of $n$-heptane and vaporization of toluene are significantly faster than that of diesel fuel, advancing the combustion phase, as shown by Cheng et al. ${ }^{15}$ Figure 3 shows the injection process and the SOC for diesel fuel at an SOI of $15^{\circ}$ CA BTDC. It was found that the ignition delays calculated from the cylinder pressure and from luminosity were not exactly the same. The SOC from the cylinder pressure data was determined as the start of the hightemperature reaction; however, for early injection timings (at lower temperatures), the camera probably could detect chemiluminescence from the cool-flame reaction at specific ignition sites. For later injection timings (at higher temperatures), combustion starts at sites throughout almost the whole of the chamber and is registered readily by the pressure sensor. Therefore

Table 4. Properties of the fuel mixtures.

\begin{tabular}{lllll}
\hline Property (units) & \multicolumn{4}{l}{ Value for the following fuels } \\
\cline { 2 - 5 } & Diesel & Heptane & $95 \%$ heptane & $90 \%$ heptane \\
\hline Carbon mass (\%fuel) & 86.96 & 84.00 & 84.37 & 84.73 \\
Fuel mass injected (mg/injection) & 5.65 & 4.65 & 4.70 & 4.75 \\
Carbon mass injected (mg/injection) & 4.91 & 3.91 & 3.96 & 4.02 \\
Carbon (\%) in fuel & 100 & 79.5 & 80.7 & 81.9 \\
Energy injected (kJ/injection) & 240.1 & 208.3 & 209.5 & 210.8 \\
\hline
\end{tabular}




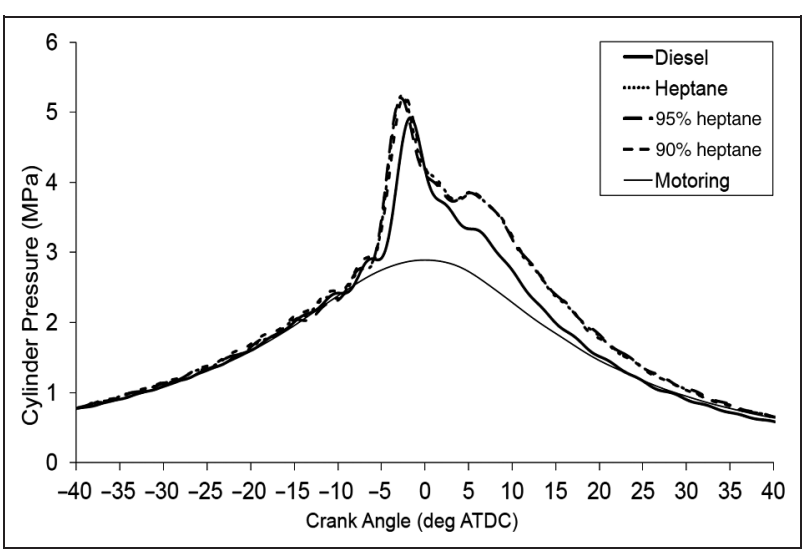

Figure 2. Pressure traces for all fuels investigated (injection pressure, $80 \mathrm{MPa}$; SOI, $15^{\circ} \mathrm{CA}$ BTDC). ATDC: after top dead centre.

the difference between the ignition delay from luminosity and the ignition delay from cylinder pressure detection is higher at early injection timings. The results obtained from in-house autoignition simulations performed using a direct-injection stochastic reactor engine model available in the reactor simulation tool DARS ${ }^{16}$ showed very good agreement with the values calculated from luminosity. Figure 4(a) and (b) shows the ignition delays calculated for the fuels analysed in this study.

From these results obtained in the optical combustion chamber, it can be seen that the ignition delays for $n$-heptane are slightly shorter than those for diesel fuel, both from the cylinder pressure data and from the luminosity data. This coincides with the higher cetane number as seen in Table 3 and probably to more rapid vaporization which enhances air-fuel mixing. The addition of toluene in small quantities does not appear to have a major influence on the ignition delay. These results are in agreement with findings in the literature ${ }^{8}$ where $n$-heptane-toluene mixtures in which the toluene percentage was kept below 10 vol $\%$ had similar ignition delays. Experiments undertaken in engines show a

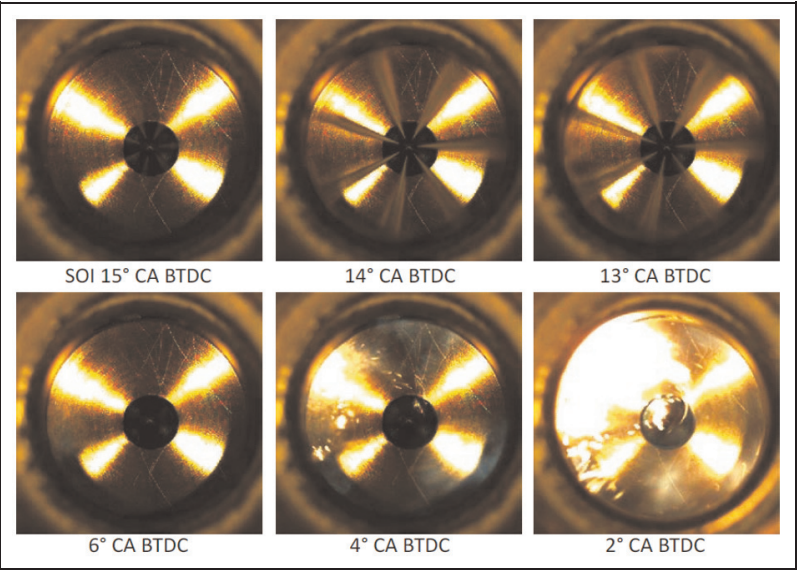

Figure 3. Injection and SOC for diesel fuel.

SOI: start of injection; CA: crank angle; BTDC: before top dead centre.

similar advance in the combustion phasing, where the premixed combustion phase is of a higher magnitude for these fuels than for diesel fuel. It should be expected therefore that the experiments shown with this optical chamber would be appropriate as a tool for the comparison of fuels.

Subsequent to the ignition comparison, a further investigation in terms of soot particle formation and emission was carried out to check whether a suitable surrogate diesel fuel had been found among the mixtures studies.

\section{Soot particle results}

The first experiments were carried out with diesel fuel to provide a basis for the results obtained with the spectrometer. 10 tests were performed under the same conditions and averaged, giving the mean and the relative deviation, to establish the repeatability of the experiments. This was performed initially with diesel fuel since the use of low-lubricity surrogate fuels can limit or adversely affect the life of current fuel injection

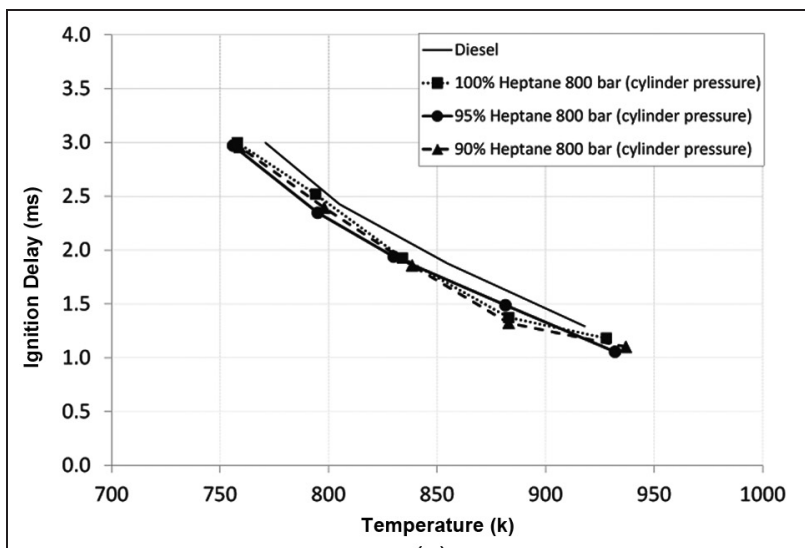

(a)

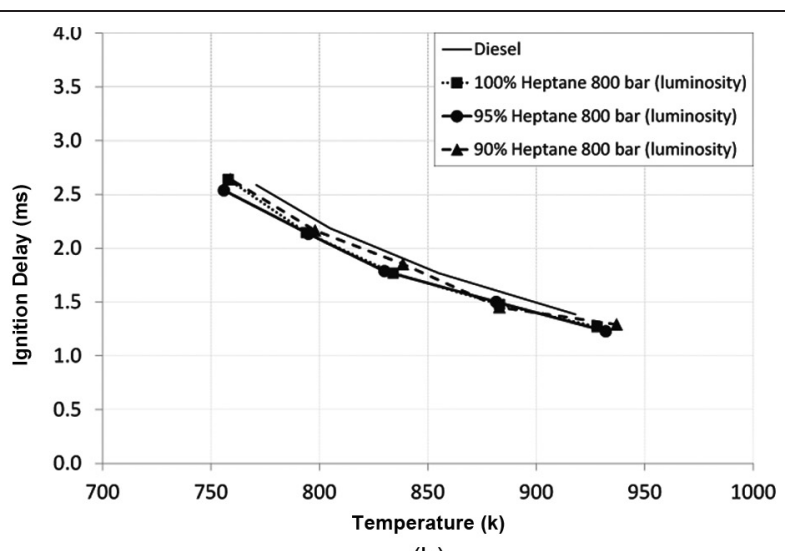

(b)

Figure 4. Ignition delays for diesel and surrogate fuels obtained from (a) cylinder pressure data and (b) luminosity data. 
equipment. Figures 5(a) and 6(a) show the particle size spectral densities for diesel fuel and the soot particle mass concentrations for diesel fuel in the nucleation and accumulation modes with the mean deviations respectively. In Figure 5(a) for particles between $1 \mathrm{~nm}$ and $100 \mathrm{~nm}$ the scale used is on the left ordinate axis and for particles between $100 \mathrm{~nm}$ and $1000 \mathrm{~nm}$ diameter on the right ordinate axis since the number density varies for these fuels by four orders of magnitude. The latest injection timing (SOI, $15^{\circ} \mathrm{CA}$ BTDC) produces the shortest ignition delay, which reesults in the shortest combustion in the premixed phase when small particles are formed and more soot during the diffusion combustion phase. As the injection timing is advanced, longer ignition delays lead to more fuel burning in the premixed phase, therefore reducing the soot emissions. However, this reduction does not happen for the earliest injection timings. This could be because a higher amount of fuel impinges on the walls, which would lead to an increase in the soot emissions. ${ }^{17}$

Figures 5(b) and 6(b) illustrate the size spectral densities for $n$-heptane and the soot particle mass concentrations for the same fuel respectively. It can be seen that, for the nucleation mode at all injection timings, the particles have the same diameter; however, the particle number is around $1 \times 10^{9}$, which corresponds to
$40 \%$ of diesel fuel. As with diesel fuel, for two late injection timings $\left(15^{\circ} \mathrm{CA}\right.$ BTDC and $20^{\circ} \mathrm{CA}$ BTDC), another peak occurs around $50 \mathrm{~nm}$ diameter compared with $40 \mathrm{~nm}$ for diesel fuel. These particles are the source of the accumulation mode mass. The largest particles appear at very low concentrations; the main difference between the results for diesel fuel and $n$-heptane is that the particles appear with a diameter of around $200 \mathrm{~nm}$ for $n$-heptane while for diesel fuel there were particles peaking at $200 \mathrm{~nm}$ and $400 \mathrm{~nm}$ diameter. For the same injection timings, for $n$-heptane, the particles produced are about $60 \%$ of the mass concentration for diesel fuel. As the injection timing is advanced, the soot emissions are reduced, as expected. This is contrary to the diesel case, probably because of the higher volatility of heptane which reduces the wall impingement, as observed elsewhere. $^{15}$

Figures 5(c) and 6(c) show the size spectral densities for the fuel mixture 95\% heptane-5\% toluene and the soot particle mass concentrations respectively. It can be observed that the addition of toluene does have an expected effect on the soot particle emission. The particle size density for almost all injection timings shows an increase in number. The two $10 \mathrm{~nm}$ and $50 \mathrm{~nm}$ peaks are noticeable for the latest three injection timings. As injection is advanced, the longer oxidation time affects

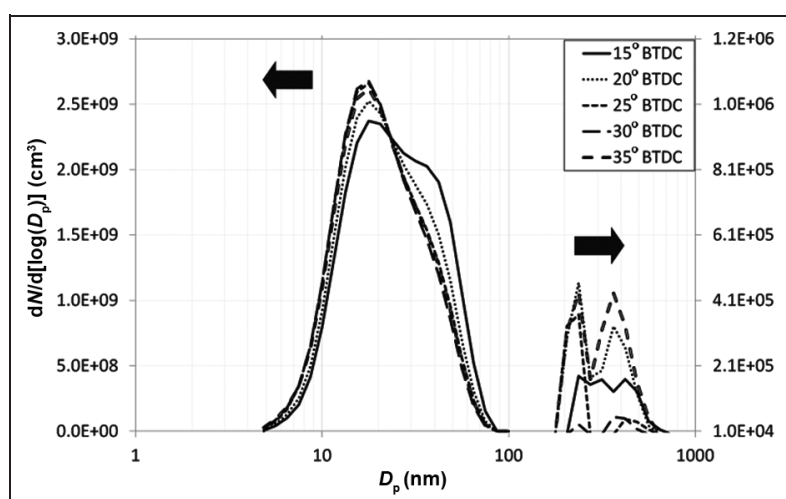

(a)

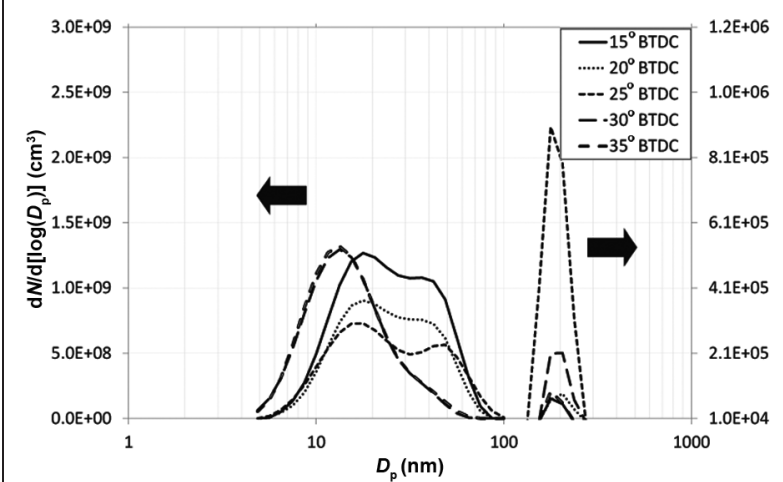

(c)

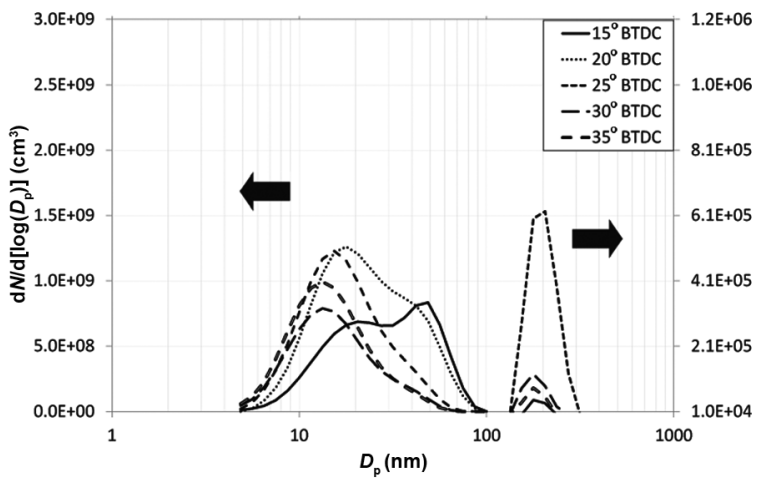

(b)

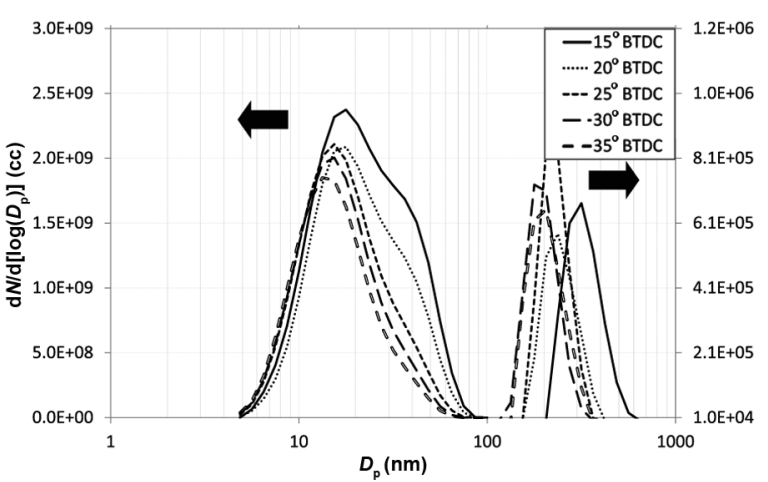

(d)

Figure 5. Size spectral particle densities for (a) diesel fuel, (b) heptane fuel, (c) $95 \%$ heptane- $5 \%$ toluene fuel and (d) $90 \%$ heptane$10 \%$ toluene fuel. BTDC: before top dead centre. 


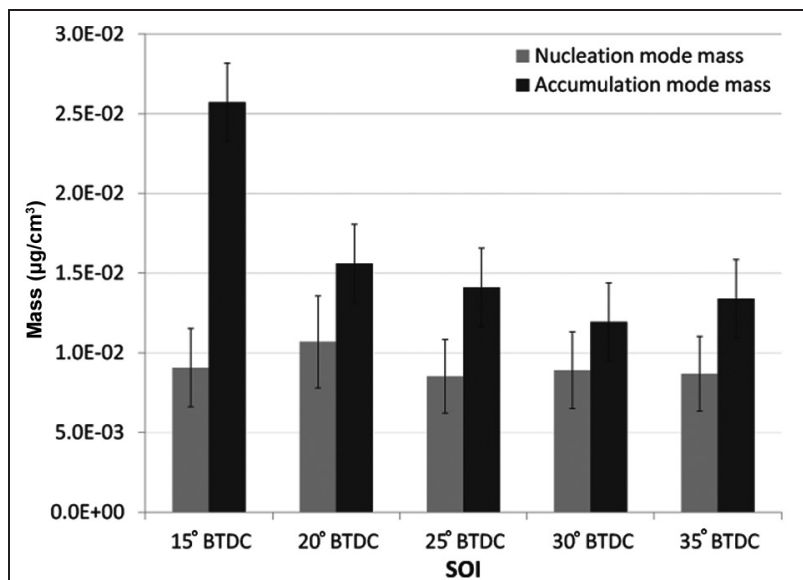

(a)

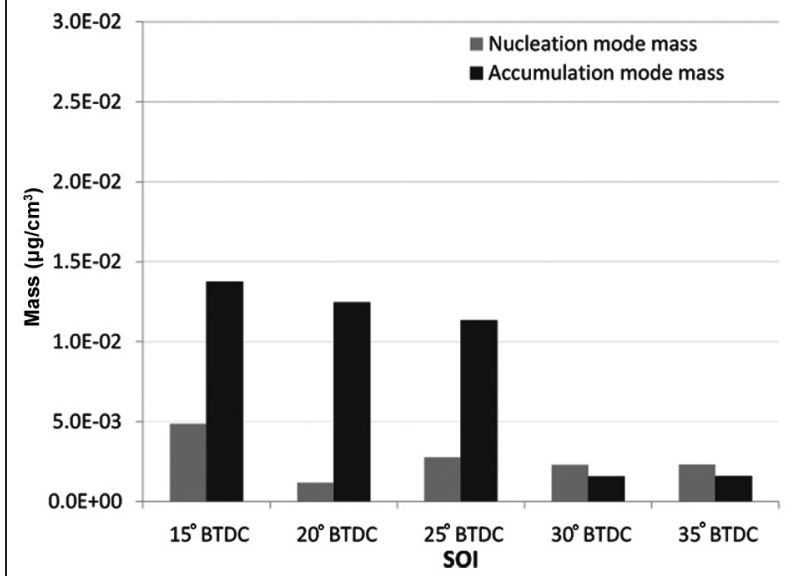

(c)

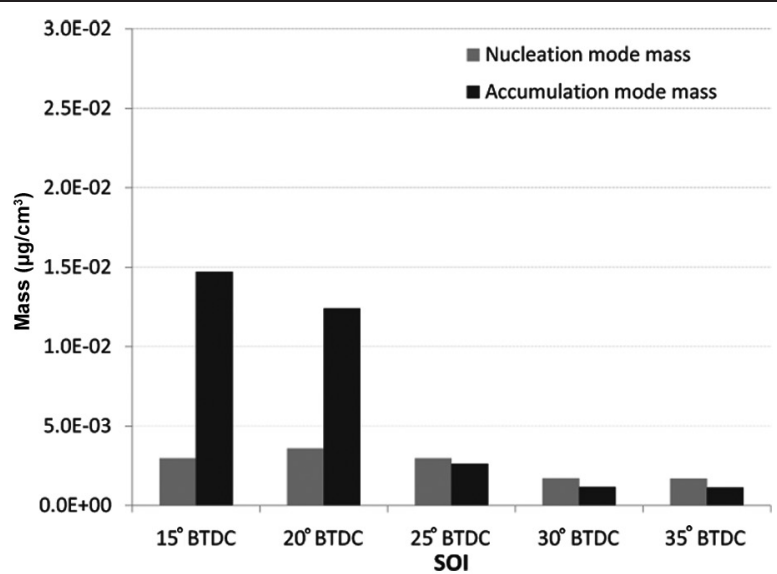

(b)

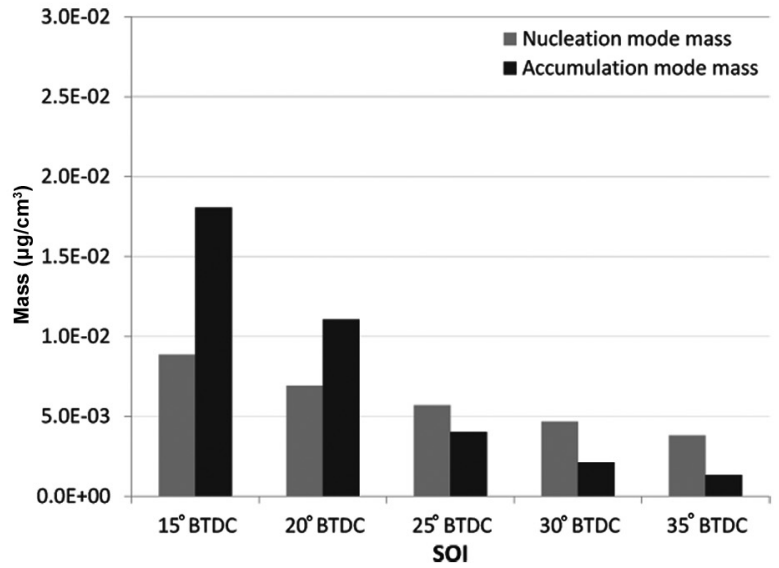

(d)

Figure 6. Particle mass concentrations for (a) diesel fuel, (b) heptane fuel, (c) $95 \%$ heptane- $5 \%$ toluene fuel and (d) $90 \%$ heptane$10 \%$ toluene fuel.

BTDC: before top dead centre; SOI: start of injection.

the size spectral density, reducing the larger particles and resulting in effectively particles of around $10 \mathrm{~nm}$ diameter.

Figure 5(d) illustrates the size spectral densities for the mixture $90 \%$ heptane-10\% toluene fuel and Figure 6(d) shows the soot particle mass concentrations for the same fuel. The addition of an extra 5\% toluene seems to have a greater effect on the particle emission. The size spectral density for particles below $100 \mathrm{~nm}$ diameter appears to be similar to that for diesel fuel. For the latest two injection timings $\left(15^{\circ} \mathrm{CA}\right.$ BTDC and $20^{\circ} \mathrm{CA}$ BTDC), peak diameters appear at around $15 \mathrm{~nm}$ and $50 \mathrm{~nm}$ and, for the earlier injection timings, only the $15 \mathrm{~nm}$ peak. The $90 \%$ heptane- $10 \%$ toluene mixture produces about $80 \%$ of the particles produced by diesel, corresponding to the difference in carbon quantities injected per stroke, as seen in Table 4. The particle agglomerates in Figure 5(d) show that the particle number for the heptane- $10 \%$ toluene mixture is higher, having a mean diameter of about $200-300 \mathrm{~nm}$. This is different from that of the diesel fuel, where the particle number is lower but exhibits two agglomerate diameters which could have originated from different aromatics in the diesel fuel composition. The values of particle mass concentration for the later two injection timings for this mixture are about $80 \%$ of those for diesel fuel, again reflecting the difference in the carbon contents injected. The earliest injection timings, however, show a larger difference, which could result from the higher volatility of the heptane-toluene mixture which reduces liquid wall impingement at lower injection temperatures, leading to reduced soot emissions, as seen in the work by Cheng et al. ${ }^{15}$

$\mathrm{N}$-heptane showed very little soot emissions compared with diesel fuel. Table 4 indicated that the total amount of carbon injected was about $80 \%$ of that for diesel; however, the soot mass measured at the exhaust was much lower. This could be expected as within the diesel fuel composition there are aromatics known to be soot promoters, as well as the volatility, as indicated in Table 3. For the same injection timings, $n$-heptane, which has a higher volatility than diesel fuel, showed longer premixed phases despite having shorter ignition delays. This difference was more significant at earlier injection timings where the higher volatility of the fuel 
as previously suggested probably reduced the amount of fuel impinging on the chamber walls.

When toluene is added into the mixture, a soot promoter is introduced. The 95\% heptane-5\% toluene showed a little increase in the soot particle mass concentration, while keeping the mean particle diameter very similar to that of $n$-heptane. However, when the amount of toluene was increased to $10 \%$, the size spectral density of the soot particles was more like that for diesel fuel, although for the earliest injection timings, the difference was greater. As for $n$-heptane, the vaporization of the mixture was more than for diesel fuel, having a greater premixed combustion phase and shorter diffusion combustion phase, which allowed less soot to be produced and a longer time for the soot formed to be oxidized.

The addition of toluene has shown, as expected, an increase in the soot particle mass concentration. To produce similar results to diesel fuel the percentage of toluene was increased to $10 \%$. This is probably because, as the combustion phase is advanced, more fuel is burned in the premixed phase and a longer time is available for any soot formed to be oxidized. In the optical chamber, where the charge is transferred to the main cylinder through the connecting tube before the exhaust, it is possible that the mean temperature of the charge could be lower than in an actual diesel engine. This would affect the oxidation rates and overall soot emissions. This effect, however, applies to all fuels and, although it could create conditions which differ from the target case of the engine in normal operation, it still provides a means of reproducibly comparing fuels.

The other major difference that these fuel mixtures exhibited in terms of soot emission was the diameter at which agglomerate particles appear to be formed. At all injection timings for $n$-heptane, agglomerates had a diameter of around $200 \mathrm{~nm}$. As toluene was added into the $n$-heptane, it was evident that there was an increase in the number of particles while generally keeping the same diameter. Diesel, however, exhibited two diameters for the particle agglomerates. This difference is possibly caused by the complex chemical composition of diesel fuel, which has yet to be mimicked under all conditions by the surrogates used.

All the fuels and mixtures examined produced different agglomerate concentrations and diameters. This could be due to the differences in the fuel aromatic composition. In this study a single aromatic component was used in the surrogate mixtures, while diesel fuel would have many aromatic species in its composition. In order to find a surrogate diesel fuel for soot particle formation and oxidation as well as initiation, other compositions adding together different aromatics ought to be considered. Although it was possible to find a fuel mixture that could replicate the soot emission behaviour of diesel fuel, this agreement was obtained only for specific conditions. The earlier-injection-timing tests showed the greatest differences. This could imply that the oxidation rates were different from those of diesel fuel. Further investigation is required.

\section{Conclusions}

In this paper, $n$-heptane and two $n$-heptane-toluene mixtures were investigated as part of a programme to find a suitable surrogate for diesel fuel. In terms of autoignition and ignition delay, heptane performed in a way similar to diesel fuel. It produced slightly shorter ignition delays, in accord with its higher cetane number. The addition of toluene to the heptane did not change the autoignition characteristics or the ignition delays and the results for all the fuels tested were very similar to those of the diesel fuel.

All experiments were carried out in an optical combustion chamber, a modification of one cylinder of a four-cylinder diesel engine. This optical combustion chamber modification is very cost effective compared with single-cylinder optical engines; however, like them, it also represents a different environment from standard operating diesel engines. The results obtained are believed to serve as a platform for fuel behaviour comparisons. In terms of autoignition, similar results have been obtained in $n$-heptane-toluene mixtures as seen in the work by Cheng et al. ${ }^{15}$ For soot analysis, more attention should be paid to the composition of the surrogate diesel mixtures. As seen in this paper, the addition of toluene did not significantly affect the ignition delay or combustion phasing. However, it did affect the soot emissions results since it increases the content of aromatic compounds. In studies of high-volatility fuels in engines, ${ }^{15}$ different aromatic compounds were employed to study the effect of volatility but, of course, this also affected the overall soot emission of the engine.

When looking at particle formation, these are the conclusions for the different mixtures.

1. Heptane. The size spectral densities for particle diameters between $1 \mathrm{~nm}$ and $100 \mathrm{~nm}$ were very similar to those for diesel fuel. However, the total number of soot particles was $40 \%$ lower than for diesel fuel. For the particle agglomerates, the particle number was of the same order; however, heptane produced a mean diameter around $200 \mathrm{~nm}$ while diesel displayed two agglomerate diameters at about $200 \mathrm{~nm}$ and $400 \mathrm{~nm}$.

2. $95 \%$ heptane-5\% toluene. The addition of toluene caused an increase in the particle number, although still not as high as the particle number for diesel fuel. The mean diameters for the nucleation mode and accumulation mode were relatively unchanged.

3. $90 \%$ heptane-10\% toluene. The addition of an extra $5 \%$ of toluene changed the size spectral density for this mixture to a value similar to that for diesel fuel. In terms of particle mass concentration 
the most retarded injection timing produced a result closer to that of diesel fuel.

All the surrogate diesel fuels produced a reduced total soot mass at the earlier injection timings. This could follow from the higher volatility of these fuels, advancing the combustion phase and reducing the liquid-fuel impingement.

\section{Funding}

As part of a search for a suitable surrogate diesel fuel, this work was supported by the Engineering and Physical Sciences Research Council (grant no. EP/ G0277730/1).

\section{References}

1. Farrell JT, Cernansky NP, Dryer FL et al. Development of an experimental database and kinetic models for surrogate diesel fuels. SAE paper 2007-01-0201, 2007.

2. Vasu SS, Davidson DF and Hanson RK. OH timehistories during oxidation of $n$-heptane and methylcyclohexane at high pressures and temperatures. Combust Flame 2009; 156(4): 736-749.

3. Gauthier BM, Davidson DF and Hanson RK. Shock tube determination of ignition delay times in full-blend and surrogate fuel mixtures. Combust Flame 2004; 139(4): $300-311$.

4. Hernandez JJ, Sanz-Argent J, Benajes J and Molina S. Selection of a diesel fuel surrogate for the prediction of auto-ignition under HCCI engine conditions. Fuel 2008; 87(6): 655-665.

5. Machrafi H, Cavadias S and Gilbert P. An experimental and numerical analysis of the HCCI auto-ignition process of primary reference fuels, toluene reference fuels and diesel fuel in an engine, varying the engine parameters. Fuel Processing Technol 2008; 89(11): 1007-1016.

6. Davidson DF, Gauthier BM and Hanson RK. Shock tube ignition measurements of iso-octane/air and toluene/air at high pressures. Proc Combust Inst 2005; 30(1): 1175-1182.

7. Mittal G and Sung CJ. Autoignition of toluene and benzene at elevated pressures in a rapid compression machine. Combust Flame 2007; 150(4): 355-368.

8. Hartmann M, Gushterova I, Fikri M et al. Auto-ignition of toluene-doped $n$-heptane and iso-octane/air mixtures: high-pressure shock-tube experiments and kinetics modeling. Combust Flame 2011; 158(1): 172-178.

9. Tree DR and Svensson KI. Soot processes in compression ignition engines. Prog Energy Combust Sci 2007; 33(3): 272-309.

10. Alexiou A and Williams A. Soot formation in shock-tube pyrolysis of toluene- $n$-heptane and toluene-iso-octane mixtures. Fuel 1995; 74(2): 153-158.

11. Alexiou A and Williams A. Soot formation in shock-tube pyrolysis of toluene, toluene-methanol, toluene-ethanol, and toluene-oxygen mixtures. Combust Flame 1996; 104(1-2): 51-65.

12. Choi BC, Choi SK and Chung SH. Soot formation characteristics of gasoline surrogate fuels in counterflow diffusion flames. Proc Combust Inst 2011; 33(1): 609-616.

13. EN 590:2009 + A1:2010 Automotive fuels - diesel requirements and test methods. Brussels: Economic Commission for Europe, 2010.

14. Abdul-Khalek I, Kittelson D and Brear F. The influence of dilution conditions on diesel exhaust particle size distribution measurements. SAE paper 1999-01-1142, 1999.

15. Cheng ASE, Fisher BT, Martin GC and Mueller CJ. Effects of fuel volatility on early direct-injection, lowtemperature combustion in an optical diesel engine. Energy Fuels 2010; 24(3): 1538-1551.

16. Wang H, Dames E, Sirjean B et al. Index of JetSurF/ JetSurF2.0, http://melchior.usc.edu/JetSurF/JetSurF2.0 (September 2010 and July 2011).

17. Martin GC, Mueller CJ, Milam DM et al. Early directinjection, low-temperature combustion of diesel fuel in an optical engine utilizing a 15-hole, dual-row, narrowincluded-angle nozzle. SAE paper 2008-01-2400, 2008. 